\title{
Cenários e perspectivas: uma análise estratégica do contexto atual e suas implicações na área dos empreendimentos de saúde
}

\author{
Henrique Maia Veloso ${ }^{1}$ \\ Sérgio Candido Dias ${ }^{2}$ \\ Fabiano Perez ${ }^{2}$ \\ Amanda Gonçalves Franco ${ }^{3}$ \\ Geraldo Alberto Pinheiro de Carvalho² \\ Aline Batista Gonçalves Franco 2 \\ Elimario Venturin Ramos \\ Silvio Mecca Junior ${ }^{2}$ \\ Caio Marques Martins ${ }^{2}$
}

Diante da complexidade do cenário, é fundamental que empreendedores possuam uma visão estratégica do contexto e suas possíveis implicações para a área da saúde. Não estamos categoricamente explicitando que os fatos derivados de toda perspectiva biológica inerente à pandemia do coronavírus sejam apenas parte de um epifenômeno transitório, mas, pelo contrário, entendemos que mudanças radicais podem acontecer na dinâmica dos negócios e sobrevivência de seus empresários.

Primeiramente, faz se entender o que vem a ser "estratégia". Por estratégia entende-se todas as ações abrangentes e de longo prazo que são realizadas por um consultório e que determinam sua sobrevivência ou competitividade. Por abrangente, deve ficar claro que isto significa que afetarão todos os setores do consultório bem como todas as áreas funcionais, tais como marketing, operações e serviços, gestão de pessoas e aspectos econômico-financeiros. Em longo prazo, com o termo já deixa claro, compreende-se que os resultados das ações talvez sejam percebidos num espectro temporal maior, ou seja, não se pode olhar apenas no que está acontecendo agora, mas quais são as consequências futuras de tais ações.
Uma das ferramentas mais tradicionais de elaboração de estratégias é a Matriz SWOT (Strengths (forças)، Weakness(fraquezas), Opportunities (Oportunidades) e Threats (Ameaças)) que procura analisar aspectos do contexto competitivo, identificando eventuais ameaças e oportunidades presentes e futuras, e diagnosticar os aspectos internos de um consultório, compreendendo os pontos fortes e fracos diante de um cenário. Neste ensaio, iremos realizar não uma análise empírica, como normalmente se faz em um cenário real de um consultório, mas uma reflexão potencial em termos de análise, pois este tipo de ferramenta geralmente se aplica a um empreendimento específico e em seu contexto real. Diferentemente, analisaremos os negócios em saúde de forma ampla e irrestrita, correndo o risco de ter, em empreendimentos diferentes, impactos diferentes do atual cenário. Mesmo cientes da possibilidade de assumir o risco de não ser preciso nas considerações, este ensaio pode gerar reflexões importantes para a área, principalmente diante de tantas novidades em termos do impacto de gestão.

\section{O contexto externo dos negócios em saúde}

Podemos analisar uma série de fatores afetando a área da saúde, bem como todos os demais negócios. Certamente as peculiaridades da área demandam reflexões específicas. Para analisar os aspectos do contexto externo, faz-se necessário analisar as grandes dimensões ou grupos

\footnotetext{
${ }^{1}$ Diretor executivo da [AZ] Saúde Profissional.

2 Faculdade São Leopoldo Mandic, Curso de Odontologia. Rua José Rocha Junqueira, 13, Swift, 13045-755, Campinas, SP, Brasil Correspondência para / Correspondence to: AG FRANCO. E-mail: <aalinebgfranco@yahoo.com>.

3 Universidade de Itaúna, Faculdade de Odontologia. Itaúna, MG, Brasil.

$\triangle \otimes \square \otimes \square$

Como citar este artigo / How to cite this article

Veloso HM, Dias SC, Perez F, Franco AG, Carvalho GAP, Franco ABG, et al. ACenários e perspectivas: uma análise estratégica do contexto atual e suas implicações na área dos empreendimentos de saúde. InterAm J Med Health 2020;3:e202003007.
} 
de variáveis. Nestes grandes grupos de variáveis, que compõem cenários de análise, temos como tradicionais as político-legais, as econômicas, as tecnológicas, as sociais, as demográficas, as ambientais, as biológicas dentre outras.

O primeiro e mais relevante grupo de variáveis a compor um cenário e a ser analisado no contexto atual é o de variáveis biológicas. A presença do coronavírus no mundo todo tem gerado grande preocupação e seus impactos na área da saúde enquanto esforços de pesquisa, mudança de procedimentos, sobrecarga dos sistemas de saúde público, além da relativa exposição dos profissionais de saúde ao risco epidemiológico são evidentes. Como isso pode afetar os negócios? Na primeira onda de impactos, logicamente, é o fato de que diversos empreendimentos estarão fragilizados por não poder atender num primeiro momento. Tais empreendimentos, principalmente os pequenos e que não dispõe de caixa e de planejamento para momentos de crise, serão diretamente ameaçados em termos de sustentabilidade. Os que não fecharem suas portas estarão severamente comprometidos com dívidas. Todavia, estes são impactos de curto e médio prazos. Em longo prazo podemos antecipar que os custos operacionais para garantir segurança biológica devem aumentar. Novos protocolos para lidar com eventuais situações de pandemia devem estar em pauta em diversos contextos legais e políticos. Entende-se que os profissionais de saúde precisam estar preparados para mercados futuros em que a certificação de segurança biológica pode ser um pré-requisito para sobreviver competitivamente. Para tanto, é preciso investir agora, para que as consequências sejam sentidas em longo prazo.

É importante que se destaque, neste sentido, que as consequências de fatos de natureza biológica irradiam para outras variáveis de grupos distintos, tais como ecológicos, político-legais, sociodemográficos. Deve-se observar, por exemplo, que consumidores começarão a se atentar mais para eventuais aspectos de segurança biológica na seleção de profissionais que irão atender. Reitera-se que este fenômeno deve se configurar, cada vez mais, em um futuro, ou seja, no longo prazo. Por tanto, entende-se como ação estratégica refletir sobre este aspecto em termos de sobrevivência competitiva do negócio.

Outro cenário de análise, que compõe também um grupo de variável, é o cenário político-legal. Observase uma forte polarização política no Brasil e a radicalização do posicionamento ideológico. Ao contrário das expectativas iniciais após as eleições, a cisão política deve persistir e se acirrar para os próximos meses. O que é diferente no contexto atual? O que se tem observado é que as mídias sociais deram uma nova dinâmica no processo político do país. Uma vez que os partidos entenderam a necessidade de manter um processo contínuo de debate para que se conquiste parte do eleitorado, as mídias sociais têm sido utilizadas como uma forte ferramenta para manter aquecida a discussão política. Neste sentido, percebe-se, diferentemente de outros anos e contextos, que após uma eleição havia um certo período de fim das discussões, com as novas formas de comunicação este processo se tornou rotina no cotidiano do cidadão comum. Percebe-se que os partidos políticos têm sido mais eficientes do que alguns consultórios que investem pesado em propagada.

Mas como isso afeta os negócios na área da saúde, principalmente em um cenário de longo prazo? Primeiramente, pela impossibilidade de prever tendências no cenário político. A todo momento cogita-se novo impeachment e isso afeta todo mercado, comprometendo investimentos e decisões importantes de empreendedores e suas consultórios. Observa-se, por exemplo, que cada ação parlamentar é direcionada para obter impacto midiático e as ações necessárias, e às vezes desagradáveis ao grande público, nem sempre são cogitadas. Um exemplo evidente deste processo é a politização do problema da pandemia de coronavírus. Os debates se constituem mais posicionamentos político-ideológicos do que essencialmente técnicos. Isso pode também ter como consequência que o posicionamento técnico de um profissional seja julgado de forma política, necessitando, sempre cautela ao expressar opiniões em um cenário que deveria ser essencialmente da ciência.

Dentre as variáveis tecnológicas, além do crescimento do setor de biossegurança, entende-se que o uso dos sistemas de comunicação e integração bem como o atendimento virtual deve crescer de forma assustadora. O home-office que antes era uma exceção, pode ser uma alternativa considerada por muitos consultórios na medida em que ela foi utilizada em larga escala mundial. Entende-se que algumas áreas da saúde também poderão ser mais acessadas desta forma, por meio do teleatendimento ou da telemedicina, promovendo a necessidade de investimento nesta área. Tem-se observado também que o suporte ao profissional de saúde de forma remota e digital também está crescendo em ações como assessoramento gerencial remoto, contabilidade digital, 
softwares de integração de negócios dentre outros. Em longo prazo, compreende-se que os profissionais que tentarem evitar tais aspectos podem se comprometer em termos de competitividade. Por outro lado, as barreiras político-legais ainda existentes em nosso país podem se constituir um restritor deste tipo de tendência. Em países como a China, este fator já é uma realidade.

Dentre os aspectos sociodemográficos mais relevantes para os próximos meses é o aumento do desemprego. Prevê-se, mesmo com o pacote do governo que injetará no mercado cerca de um trilhão de reais, o aumento da taxa de desemprego é inevitável, bem como a queda no crescimento. Por isso mesmo, a fragilização das camadas mais simples da população, o aumento da inadimplência, o aumento da desigualdade social serão fatores com os quais teremos inevitavelmente que conviver por um tempo, significando essencialmente a redução do consumo. Deve-se observar que empreendimentos da área da saúde direcionados para essas parcelas da população podem sofrer mais neste contexto dos próximos anos, pela redução da demanda e priorização de consumo para outras áreas, uma vez que nem sempre a saúde é vista como investimento ou gasto essencial.

No cenário econômico veremos um aumento do endividamento do Estado em curto prazo, mas que se pode agravar com o desaquecimento da economia. Isto significa que ações políticas no sentido tributário ou fiscal poderão ser tomadas para equilibrar as contas públicas. A forma como o governo federal irá se posicionar pode ser um grande fator determinador do cenário, que pode culminar em pressão inflacionária, estagnação ou a estagflação (que é a combinação de ambos constituindo o pior dos cenários). Também existe uma pressão forte quanto ao valor do dólar no mercado na medida em que o governo irá justamente buscar recursos para promover a retomada do crescimento econômico, podendo desencadear uma desvalorização do real frente ao dólar.

Tudo isto mostra a complexidade do cenário atual e do conjunto de variáveis que podem se constituir ameaças ou oportunidades para os empreendedores da saúde. Por isso, é preciso avaliar quais são as perspectivas internas dos negócios da saúde no Brasil.

\section{O contexto interno dos negócios em saúde}

A primeira e grande questão que é preciso levantar nos aspectos internos dos negócios em saúde é a falta de cultura em gestão. O empresário da saúde no Brasil sabe ser excelente em atendimento, mas fraco em em gestão. Em geral, são poucos os que possuem um sistema formal e articulado de gestão estratégica, integrando aspectos de planejamento de curto, médio e longo prazos, sistemas de gestão e integração do negócio, organização, controle dentre outros processos e procedimentos essenciais para sobrevivência em ambientes de crise. É fácil fazer funcionar um consultório quando a economia está crescendo e é possível errar muito. Embora nossos últimos anos não fossem essencialmente de crescimento exagerado, mas a própria carência existente de profissionais da saúde em algumas áreas permitiu crescimento de consultórios no setor. 0 que se tem que dimensionar agora é que o contexto mudou para uma crise severa que pode excluir aqueles que não estão preparados gerencialmente.

A própria falta de cultura de gestão e planejamento pode desencadear a o próximo aspecto na grande maioria dos empreendimentos de saúde que é a falta de liquidez do empreendimento. Poucos empresários possuem a consciência de não imobilizar seus recursos, gerindo as despesas de seus empreendimentos com o faturamento do respectivo mês. A ausência de planejamento é sentida justamente por não gerar caixa para eventualidades e fatos que aconteçam. Quantos empresários da saúde sabem realmente os custos reais de seus procedimentos por paciente? O uso excessivo de cartão de crédito, cheque-especial são armadilhas frequentes que podem ser observadas como práxis empresarial e que em um momento de fragilidade do negócio comprometem a sustentabilidade e sobrevivência dele. Neste sentido, deve-se observar diversos empreendimentos entrando em situação crítica nos próximos meses, não necessariamente pelo problema contextual, mas pela falta de preparação para situações como esta que são plausíveis.

Em termos operacionais, acredita-se que a grande maioria dos profissionais de saúde não está plenamente preparada para atuar nos cenários previstos de biossegurança e teleatendimento. Não se trata necessariamente de conhecimento do profissional, mas do investimento feito em equipamentos, estrutura, treinamento de equipes para lidar com os dois aspectos. Entre o conhecimento para fazer e a execução existe o distanciamento da prática operacional, ou seja, do modus operandi de um consultório. Ao mesmo tempo, as práxis atuais de atendimento mostram uma falta pensamento gerencial. Um exemplo claro neste sentido é que as salas de espera em consultórios são ainda sempre cheios, com a ideia de que fazer o paciente esperar e a melhor maneira de ampliar o faturamento. É preciso 
transformar os consultórios nos aspectos operacionais e repensar os empreendimentos para serem mais eficientes e otimizados.

Mercadologicamente, pela ausência da compreensão do cenário político e das conexões com as práticas mercadológicas, tem-se observado o posicionamento de diversos profissionais da saúde, tanto no que diz respeito à polarização política quanto a polarização científica quanto ao isolamento social como estratégia para lidar com o risco do contexto de pandemia. Antes que este aspecto efetivamente se consolide como um ação de respaldo científico, o que se quer discutir essencialmente e o risco de se posicionar publicamente num contexto que não está preparado para a discussão científica ou técnica, mas para avaliar qualquer fala como essencialmente ideológica. Neste sentido, entende-se que tais ações podem se constituir como fragilidades aos empreendimentos de alguns profissionais, pois podem gerar rejeição pública no atual contexto. É preciso entender que a discussão científica deve ficar restrita aos meios acadêmicos de debate, onde a oposição e a contradição de ideias representam a essência desta instância. No meio empresarial, a exposição pode-se tornar um fator gerador de restrições de mercados futuros e de públicos-alvo específicos.

No que tange a gestão de pessoas, entende-se que dois aspectos podem ser relevantes na consideração dos empreendimentos. O primeiro deles é o fato de que representam boa parte dos custos fixos de um consultório e que num primeiro momento devem sofrer um impacto quer seja na renegociação das condições de trabalho, quer seja no aumento da oferta de mão de obra em decorrência do desemprego. Ou seja, novas formas de relação de trabalho podem ser estabelecidas neste novo contato. Ao mesmo tempo, observa-se um despreparo dos profissionais disponíveis, principalmente dos auxiliares, no que diz respeito à biossegurança e ao uso da tecnologia para atendimento operacional e gestão. Será preciso capacitar profissionais para trabalhar em um novo contexto. Surge uma nova oportunidade para as estruturas de ensino.

\section{Perspectivas e Recomendações}

Diante dos diferentes cenários, o planejamento estratégico se torna extremamente complexo, pois o grau de imprevisibilidade destes contextos é mais elevado. Não é possível, por exemplo, quais serão as medidas adotadas pelas instâncias governamentais federais, estaduais e municipais, bem como não se sabe como o o problema biológico do coronavírus irá, necessariamente, se desenrolar. Desta forma, recomenda-se pensar em três cenários distintos.

No primeiro cenário, o qual chamamos de cenário positivo, as medidas de contenção e isolamento social surtem o efeito acima do esperado resultando num crescimento aceitável dos casos, permitindo que a estrutura pública e privada de saúde consigam absorver os impactos da demanda por atendimento.

Neste cenário, otimista, não serão necessários mais do que 15 dias para que se volte à normalidade social.

Em um cenário intermediário, as ações de contenção precisam durar, pelo menos 30 dias, com impacto significativo nos empreendimentos de forma que a reversão das condições econômicas do país pode perdurar pelo menos um ano. Neste cenário o impacto será sentido em todos os setores econômicos, mas de forma distinta.

Por fim, no cenário negativo, entende-se que o processo todo pode durar até três meses, com períodos intensos de contenção social e restrição, alternando com processos de gradativo relaxamento das ações de isolamento social. Neste cenário, mais grave econômica e socialmente, o impacto econômico pode ser sentido pelos próximos anos, tendo diversas consequências no país.

Não é possível construir uma previsão segura de qual contexto efetivamente se consolidará. E esta não é, necessariamente uma questão do planejamento estratégico em si, pois prever exatamente o que vai acontecer é impossível. Todavia, é necessário que o profissional de saúde análise qual é o impacto de cada cenário em seu consultório. Ou seja, é preciso pensar em ações que deverão ser feitas em cada possível situação para justamente antecipar os eventuais problemas antes que eles se tornem realidade. Criar ações para cada cenário é pensar estrategicamente.

Começar a construir uma cultura de gestão no empreendimento é outra ação fundamental para sobrevivência nestes tempos incertos. Pensar em todos os aspectos organizacionais e começar a decidir com base em sistemas de apoio a gestão. O profissional da saúde precisa parar de se preocupar apenas com o atendimento e começar a pensar como empreendedor, vendo na gestão sua maior aliada para lidar com a competitividade e sobrevivência do negócio.

O investimento em biossegurança, que se entende aqui como sendo não o só a aquisição de equipamentos, mas também como a mudança de protocolos nos ambientes de trabalho e capacitação da equipe deve ser 
uma preocupação a ser considerada como ação de médio e longo prazo. Paralelamente, deve-se avaliar a perspectiva de formas alternativas de incorporar a tecnologia em tempos de teletrabalho. A otimização do tempo dos profissionais e de seus pacientes deve ser considerada como uma tendência inexorável.

Uma recomendação de curto prazo imediata é a cautela na exposição pública de suas opiniões em questões que podem polemizar ou fazer parte da dicotomia política que estamos vivendo. É mister que ele continue a geração ações de marketing e propaganda, mas atentando-se meticulosamente para que suas manifestações, sejam pessoais ou profissionais, não se posicionem efetivamente para uma direção que entendemos que ainda é incerta. As discussões técnicas devem, a nosso ver, ficar restritas ao meio acadêmico e, neste momento, longe das redes sociais. De forma muito mais intensa, recomenda-se cautela no posicionamento político.

Compreender sua equipe, entender quais são os melhores profissionais e investir neles é algo que deve ser um pensamento constante. Todavia, entende-se que, dependendo do cenário, reduções aconteçam justamente para que se evite o pior, ou seja, entrar num estado de insolvência irreversível. É fundamental que se pense de forma criteriosa como tomar essas decisões complexas e forma como irá lidar com a situação, pois isso poderá contaminar todo empreendimento. Há técnicas e formas de se realizar este processo e o profissional da saúde precisa estar bem assessorado de profissionais experts em gestão para planejar todo este processo, envolvendo advogados, contadores e gestores.

Não há mais espaço para uma gestão amadora e isso ficará, cada vez mais evidente. Certamente a crise vem para todos, mas apenas aqueles que estiverem melhor preparados gerencialmente sobreviverão enquanto negócios. Não basta apenas ser melhor tecnicamente para que um empreendimento seja competitivo, sustentável e sobreviva em tempos de incertos.

\section{REFERÊNCIAS}

Kim WC, Serra AC da C, Mauborgne R. A estratégia do oceano azul: como criar novos mercados e tornar a concorrência irrelevante [Internet]. Elsevier; [cited 2020 Mar 28]. Available from: http://search.ebscohost.com/ login. aspx? direct=true\&db=cat06909a\&AN=sib.413943\&l ang=pt-br\&site=eds-live
Mintzberg H. Safari da estratégia um roteiro pela selva do planejamento estratégico [Internet]. Porto Alegre: Bookman; 2010 [cited 2020 Mar 28]. Available from: http://search.ebscohost.com/login.aspx? direct=true \&db=e dsmib\&AN=edsmib.000000695\&lang=pt-br\&site=eds-live 